\title{
Patología de las toxemias del embarazo en madres e hijos
}

\section{Doctor Saullo Muñoz_Delgado}

Auxiliar de Cátedra de Obstetricia, Facultad de Medicina. Universidad del Valle. Jefe de Residentes de la Clínica de Maternidad de Cali.

\section{Doctor Oscar Henao_Cabal}

Auxiliar de Cátedra de Obstetricia, Facultad de Medicina. Universidad del Valle. Jefe de Residentes de la Clínica de Maternidad de Cali.

Este trabajo es una comunicación preliminar sobre los estudios que estamos adelantando desde hace aproximadamente dos años y medio sobre la Patología de la Toxemia gravídica en nuestro medio.

Las toxemias del embarazo siguen siendo un tema ampliamente debatido tanto en su etiología como en su patología. Aún existe controversia sobre si afecciones cuyas lesiones son regresivas después del cuadro toxémico, como las alteraciones vasculares renales y hepáticas, sean la causa determinante de la muer. te, o si son solamente efectos en el extenso cuadro de la patología de las toxemias.

Una de las dificultades diagnósticas es la diferenciación entre el cuadro clínico del coma eclamptico y el de las entidades aso_ ciadas a convulsiones y coma u otros síntomas cerebrales. Es pre. cisamente aquí en donde los estudios de Patología van a diluci. dar el diagnóstico. En nuestro estudio encontramos dos pacientes que habian sido clasificadas como eclámpticas por presentar un cuadro de convulsiones, hipertensión, edema y albuminuria, pe_ ro que debimos descartarlas porque sorpresivamente la patología uos descubrió que se trataba de un caso de meningitis T. B. C. y otro de poliomielitis anterior aguda.

Por eso, cuando decidimos entrar a contribuir al estudio de las toxemias gravídicas, problema siempre actual y progresivo, consideramos que era necesario iniciarlo con la Patología. He'- 
mos estudiado los hallazgos patológicos en nuestro medio, comparándolos con los resultados de Bartholomew, Colvin, Page, Diec_ kmann y Theobald.

Al presentar esta contribución debemos agradecer al Departamento de Patología de la Facultad de Medicina de la Universidad del Valle, y especialmente al doctor Pelayo Correa, las facilidades que proporcionó a nuestro empeño no solamente poniendo a nuestra disposición las instalaciones y dotación a su cargo sino contribuyendo con su aporte personal en el ciclo de conferencias sobre toxemias que se dictaron hace un año en Cali patrocinadas por la Sociedad Vallecaucana de Obstetricia y Ginecología.

\section{A T E R I A L}

El material utilizado en nuestros estudios proviene de pacien. tes del Departamenta de Toxémicas de la Clínica de Maternidad de Cali y un caso de la Sección de Maternidad del I.C.S.S. El estudio clínico de las pacientes ingresadas al Departamento de Toxemias ha estado bajo la supervisión de los doctores Alberto Naranjo, internista y cardiólogo y Jorge Solanilla, obstetra. Las autopsias estudiadas representan el $\mathbf{8 3 . 3 \%}$ de las muertas con toxemia. Este alto índice de autopsias lo hemos logrado gracias a que como requisito previo a la admisión de cualquier tipo de pacien. te que busque los servicios de la Clínica se la hace firmar por ella o por sus familiares o allegados la autorización para practicar "to. da clase de exámenes, inclusive post-mortem en la paciente o en su hijo". Asi hemos obviado con la sola excepción de dos casos el grave problema de todos conocido que representa el tratar de convencer a los familiares de una paciente, después de que ha muerto ésta, de que se dé al hospital la autorización para practicar el examen post-mortem. Los dos casos en los que no se pudo practicar autopsia fueron de muertas precisamente antes de la implantación del requisito anotado. Por lo tanto debemos aclarar que en los dos últimos años hemos obtenido $100 \%$ de autopsias.

Este número de autopsias revela al mismo tiempo la mortalicad que hemos tenido por toxemias en la Clínica de Maternidad. En 33 meses, contados entre el 1 o de enero de 1955 y el 1 o de octubre del corriente año, han muerto 12 pacientes con toxemia so_ bre un total aproximado de 13.600 hospitalizaciones.

Aun cuando este índice de mortalidad no es alto, al sacar los indices de mortalidad depurada sobre el número de autopsias, podemos descartar por lo menos 3 de los 10 casos, ya que permane- 
cieron en la Clínica menos de 5 horas antes de su muerte. Por lo demás cabe anotar que solamente una de las pacientes había asistido a control prenatal y es sabido que el pronóstico de la toxemia depende de la prontitud del diagnóstico y de la institución del tratamiento (Cuadro número 2).

Si bien este trabajo se refiere básicamente a la patología de las toxemias, no queremos dejar pasar por alto el hecho de que en los 10 casos hubo 2 mortinatos y 5 sin parto (muerte in útero), y solamente se obtuvieron 3 niños vivos. De éstos 1 por cesárea post-mortem; la paciente presentó un cuadro de pre-eclampsia sobre impuesta a una enfermedad hipertensiva e hizo edema agudo pulmonar con un embarazo de 38 semanas. Otro fue un parto iniervenido con fórceps medio bajo en una paciente con embarazo a término con pre-clampsia severa. De los siete fetos muertos solamente en un caso hubo parto espontáneo en casos de abruptio placentae (Cuadro número 2).

La alta incidencia de pérdida fetal se explica por elevado número de eclampsias, la prematurez y la falta de control prenatal.

De esta manera y resumiendo, encontramos que seis de las pa. cientes murieron sin haber tenido su parto, con promedios de embarazos de 30 a 36 semanas; dos murieron después de parto espontáneo, una después de aplicación de fórceps y otra ocho días después de la cesárea en que se produjo una dehiscencia de la su_ tura segmentaria (Cuadro número 3 ).

Las edades de las pacientes fluctuaron entre los dieciséis a los cuarentaitrés años (Cuadro número 1).

Por lo que se refiere al tipo de toxemia, hubo una pre-eclamp_ sia leve, tres con pre-eclampsia severa: cuatro con eclampsia y dos con hipertensión y pre_eclampsia sobre-agregada (Cuadro nú. mero 4).

Causa de muerte. Analizando las causas inmediatas de muerte podemos resumirlas en el Cuadro número b.

Nos llama la atención la alta incidencia del edema agudo pulmonar que se presentó en cinco pacientes, as como la hemorragia cerebral en dos.

Estas cifras están de acuerdo con las presentadas por Dieckman en un promedio de 19 autopsias (Cuadro número 6).

En el cuadro siguiente (Cuadro número 7) hemos querido analizar la relación entre la gravedad de la toxemia y la causa in. mediata de la muerte. Encontramos que hay también 3 casos de 
muertes calificadas por nosotros como evitables (subrayadas): un caso de pre-eclampsia leve con muerte de la paciente con accidente anestésico durante la aplicación del forceps (atelectasia pulmonar); otra en el cual se practicó cesárea por abruptio placentae, con gran hipertonia uterina, dolor intenso y hemorragia profusa no habiéndose conseguido la iniciación del trabajo de parto a pesar de la inyección con Pitocín y la amniotomía. Da_ das las malas condiciones de la paciente, anemia e hipoproteine. mia, presentó una dehiscencia de la sutura segmentaria muriendo a los 7 dias por una peritonitis fibropurulenta generalizada. El tercer caso llegó a la Clínica, después de ruptura precoz de membranas y presentó una endometritis gaseosa que se diseminó dando focos de gangrena gaseosa al riñón y al hígado.

CUADRO NUMERO :

Edad de las pacienties

$\begin{array}{rr}16-20 & 2 \\ 20-30 & 6 \\ 30-40 & 1 \\ +\quad 40 & 1\end{array}$

CUADRO NUMERO 2

Tiempo de permanencia en la clínica y clase de parto

$\begin{array}{lll}\text { A-55-103 } & 1 \text { hora } 25 \text { minutos } & \text { Sin parto. } \\ \text { A-57-204 } & 2 \text { horas } 30 \text { minutos } & \text { Espontáneo, vivo. } \\ \text { A-57-202 } & 5 \text { horas. } & \text { Sin parto. } \\ \text { A-57-124 } & 10 \text { horas } & \text { Fórceps vivo. } \\ \text { A-56-1 } & 10 \text { horas } & \text { Sin parto. } \\ \text { A-56-34 } & 2 \text { días } & \text { Sin parto. } \\ \text { A-56-83 } & 2 \text { días } 11 \text { horas } & \text { Cesárea post_mortem. } \\ \text { A-56-33 } & 6 \text { días } & \text { Espontáneo. } \\ \text { A-57-180 } & 9 \text { días } & \text { Cesárea. } \\ \text { A-55-46 } & 14 \text { días } & \text { Sin parto. }\end{array}$


CUADRO NUMERO 3

Edad del embarazo en semanas-Tipo de parto y supervivencia fetal

30-32 Semanas Semanas Parto

A-55-46

A-56-1

A $-57-202$

32 -36 semanas

A- $56-34$

A $-57-180$

A $-56-33$

30 Sin parto

30

30

32

Sin parto

Cesśrea (Abruptio)

Espontáneo
Supervivencia fetal

Muerte Intrauterina

"

,

36 -40 semanas

$\begin{array}{llll}\text { A-56-83 } & 38 & \begin{array}{l}\text { Cesárea } \\ \text { Post_mortem }\end{array} & \begin{array}{l}\text { Vivo } \\ \text { Auerte Intrauterina }\end{array} \\ \text { A-55-103 } & 37 & \text { Sin parto } & \text { Vivo } \\ \text { A -57-124 } & 40 & \text { Fórceps } & \text { Vivo } \\ & 40 & \text { Espontáneo } & \\ & & \\ & & \end{array}$

Clasificación del tipo de toxemia

1-Pre_eclampsia leve

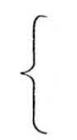

A $-57-124$

3-Pre-eclampsia severa

\{

A-57-180

A $-56-1$

A $-57-204$

4-Eclampsia

A $-55-46$

A $-55-103$

A- $56-83$

A $-56-34$

2-H.C.V.D. con Pre_eclampsia sobreagregada

A $-56-33$

A $-57-202$ 


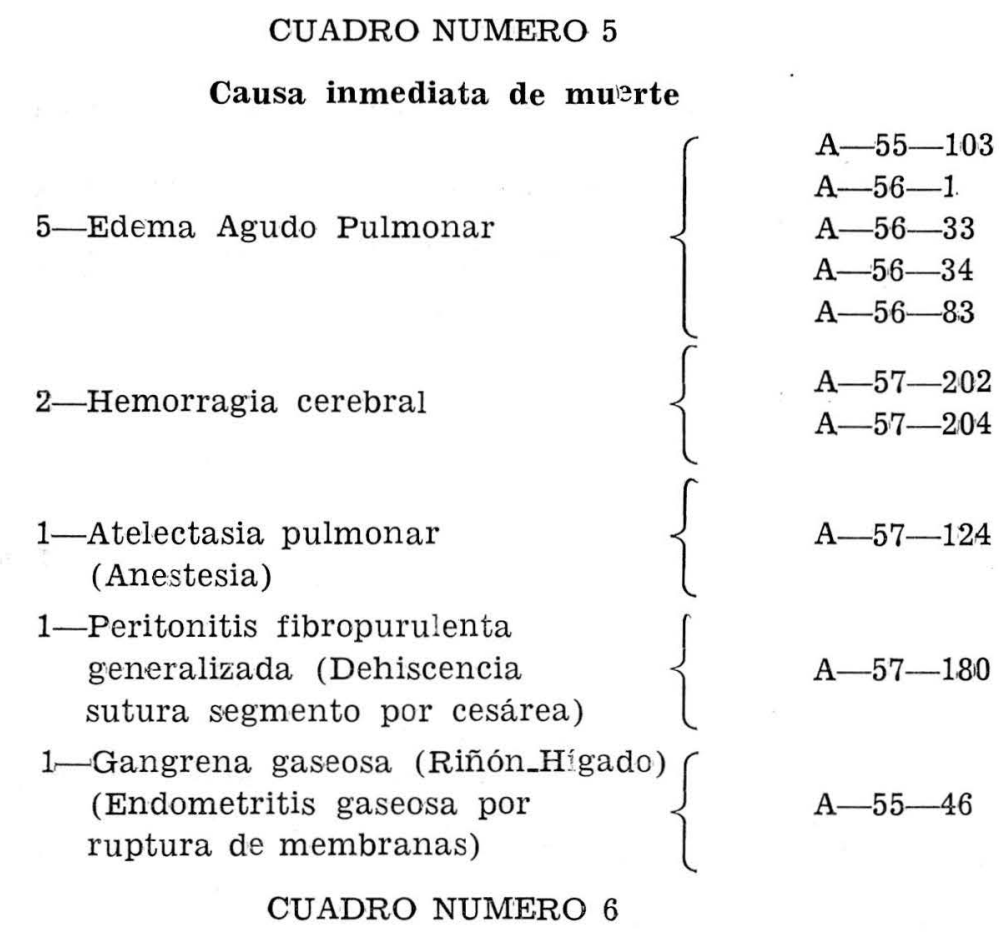

Causa de muerte

182 eclámpticas
19 murieron

Insuficiencia circulatoria

Afibrinogenemia

Hemorragia cerebral

Parálisis respiratoria

Ruptura útero

Peritonitis
Dieckmann

9

9

3

1

1

1.

\section{CUADRO NUMERO 7}

\section{Relación entre tipo de toxemia y causa de muerte}

1-Pre_eclampsia leve A-57-134 Atelectasia pulmonar (Anestesia)

A-56-1 Edema agudo pulmonar

3-Pre-eclampsia severa A-57-204 Hemorragia cerebral

A $-57-180$ Peritonitis fibrinopurulenta

(Dehiscencia sutura segmento)

A-55-46 Gangrena gaseosa (Endometritis gaseosa)

4-Eclampsia A-55-103 Edema agudo pulmonar

A-56-1 Edema agudo pulmonar

A-56-34: Edema agudo pulmonar

2-H.C.V.D. con pre $-A-56-33$ Edema agudo pulmonar

eclampsia sobreagregada A $-57-202$ Hemorragia cerebral 


\section{PATOLOGIA DEL HIGADO}

El estudio de la patología del hígado lo hemos practicado con el material de las autopsias y las biopsias hepáticas en pacientes con toxemia leve, severa y eclampsia.

En esta forma tratamos de averiguar si las lesiones son simplemente un grado en la severidad de la toxemia o si estas lesiones son constantes en todos los casos.

Algunos autores consideran que la severidad de la toxemia es menos influyente en la lesión hepática que la duración de la enfermedad. En algunos casos clasificados como toxemia leve pero con un período de evolución de mes y medio, encontramos le. siones más características que en casos de pre_eclampsia severa de evolución rápida.

Aspecto macroscópico.-Parece que el tamaño del hígado no tenga una alteración precisa encontrándose de diferentes pesos que fluctuaron desde los 950 gramos hasta los 2.200 promedio alrededor de 1.700 gramos. El aspecto externo presenta zonas hemo. rrágicas en forma de manchas o parches distribuidos en todo el hígado y con mayor frecuencia número e intensidad localizados en el lóbulo derecho. Estas hemorragias constituyen las hemorragias sub-capsulares, cuyo diámetro varía llegando a encontrar f'n uno de los casos un coágulo de 1 centímetro. Encontramos este tipo de hemorragia en forma marcada en cuatro casos, y en uno

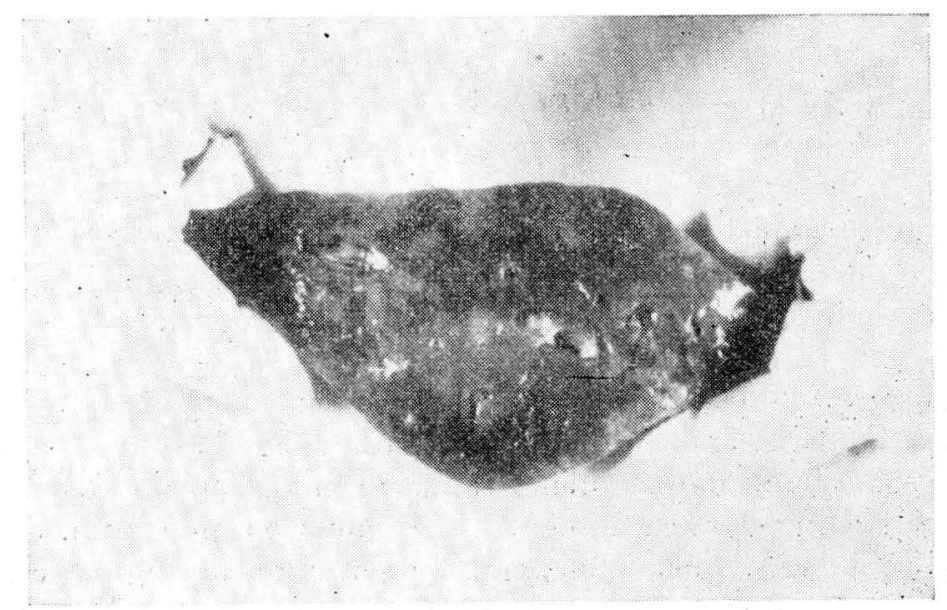

HIGADO--Aspecto macroscópico, corte transversal. Hemorragia distribuída en todo el parénquima. 


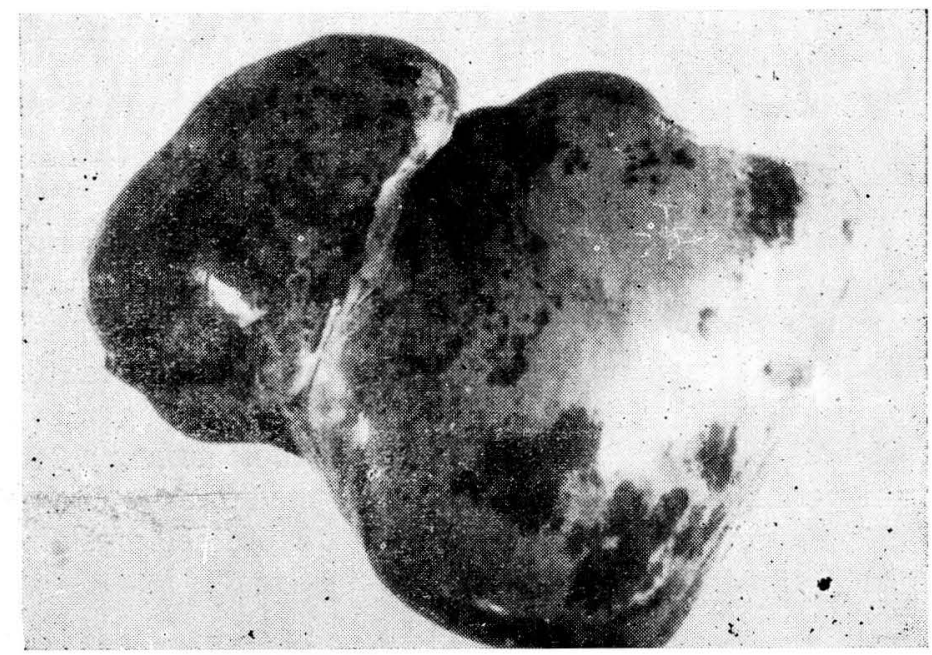

HIGADO.-Aspecto macroscópico. Zonas hemorrágicas subcapsulares diseminadas.

de ellos se extendía en el corte transversal a grandes áreas del parenquima hepático (A-57_202 y A-57-124, etc.).

Otros han descrito una lesión en forma de "nuez moscada" debido a su aspecto de zonas alternas grises, blancas y rojas, la que encontramos en dos de los casos. Además este cambio ocurre también cuando hay una insuficiencia cardíaca. Las lesiones descritas como áreas de necrosia anémica por Schmol que pueden tener un tamaño hasta de 2 centímetros y ser de color blanco amarillento o puramente blancas, las pudimos encontrar en uno de los casos (A_55-103).

En los cortes de hígado que practicamos se encontró un co_ lor pálido o amarillento y algunas zonas hemorrágicas.

El color ictérico encontrado en el cuerpo de algunas toxémicas, no nos fue posible identificarlo en nuestra serie.

Aspecto microscópico.-El cuadro esencial es el de una hemorragia originada en los vasos periportales, con lesiones determinadas por la cantidad de hemorragia. Se inicia en el espacio portal, extendiéndose hacia el centro del lóbulo. Se presentan en una forma irregular y pueden llegar a ocupar todo un campo microscópico de un objetivo panorámico. Estas áreas irregulares de necrosis hemorrágicas según Dieckmann, son la explicación de los resultados tan variados que se han publicado. Nos fue fácil com- 


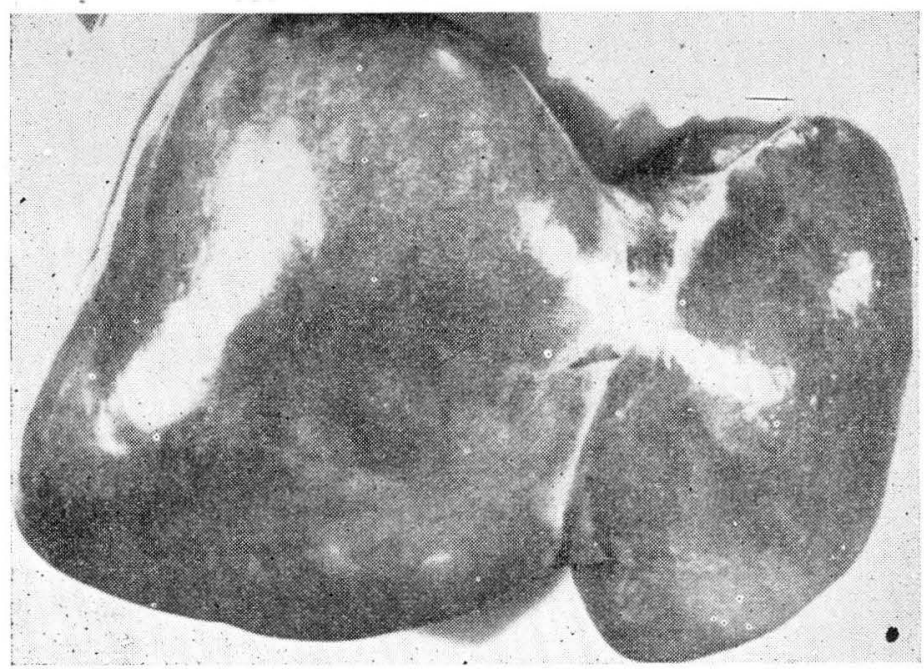

HIGADO.-Aspecto macroscópico. Lesión en forma de "nuez moscada".

probarlo debido a que en muchos cortes encontramos zonas centrales de necrosis hemorrágica, que al haber practicado la biop. sia por punción tal vez no hubiéramos podido alcanzar.

Para algunos (Pilliet) la lesión primaria es una marcada dilatación y ectasia de los capilares alrededor del espacio portal, mientras que otros (Schmorl) creen que la dilatación y hemorra. gia ocurren simultáneamente.

Theobald atribuye esta necrosis a la fibrina junto con la san_ gre que se sale del vaso alterado, se coagula y forma una masa fibrino_hemorrágica. Esto puede ser el origen de la necrosis determinada por cantidad de hemorragia.

Las células hepáticas se van comprimiendo a medida que au_ menta la dilatación, congestión y trombosis de los sinusoides hepáticos y terminan luego necrosándose debido a la falta de oxígeno y nutrición adecuada. En los casos más avanzados las células parenquimatosas son desprendidas de sus envolturas y posteriormente mueren.

En los casos de viejas lesiones de 24 a 72 horas de duración, los eritrocitos degeneran y se disuelve su hemoglobina formando gránulos o pigmentos ocres. La fibrina se transforma en una sóli. da masa y se constituyen focos de estructuras necróticas.

Dieckmann anota que estos hallazgos son poco frecuentes en pacientes cuyos partos o recuperación de los ataques eclámpticos 


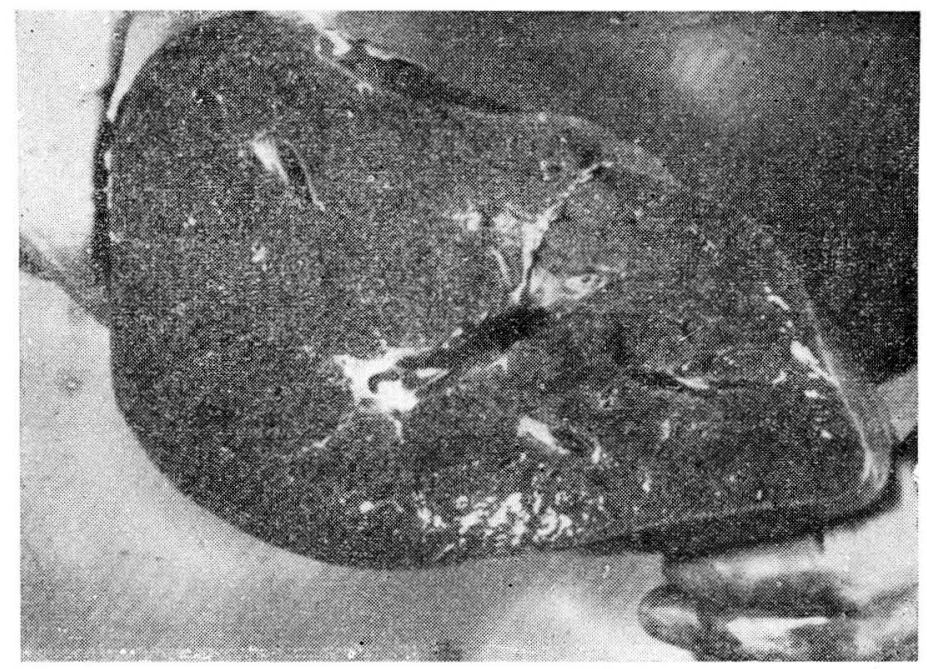

HIGADO.-Aspecto macroscópico. Corte transversal. Aspecto típico de "nuez moscada".

hayan ocurrido unos dias antes de la autopsia. Esto lo comprobamos en una paciente (A-57-180) y en varios casos de biopsia, estudios que fueron practicados 6 a 8 dias después del parto o del ataque eclámptico. En estos casos apreciamos un cuadro regenerativo caracterizado por hepatocitos con dos núcleos.

Los infartos anémicos son más raros y las células hepáticas se encuentran edematosas, con un protoplasma que se tiñe muy pobremente (A_55-103). Los núcleos están ausentes o solamente se distinguen como gránulos irregulares. Los sinusoides en estas áreas frecuentemente se hallan obliterados por trombos hialinos, lo que le dá un aspecto vacio a las zonas centrales de estos si. nusoides.

En la descripción de esta lesión, Dieckmann señala leucocitos que se acumulan en la periferia de las áreas necróticas al mis. uno tiempo que hay migración dentro de la porción central. Estas áreas son pequeñas y casi siempre se encuentran cerca al tejido conectivo periportal.

Los indices de la insidencia de la necrosis periportal varía desde el $50 \%$ (Tenney) hasta más del $80 \%$ (Schmorl). Esta necrosis puede extenderse a uno o más lóbulos hepáticos.

Las lesiones focales se producen por hemorragias dentro de las columnas hepáticas cerca del espacio portal haciendo que las células hepáticas se desplacen hacia el centro del lobulillo. Dieck- 


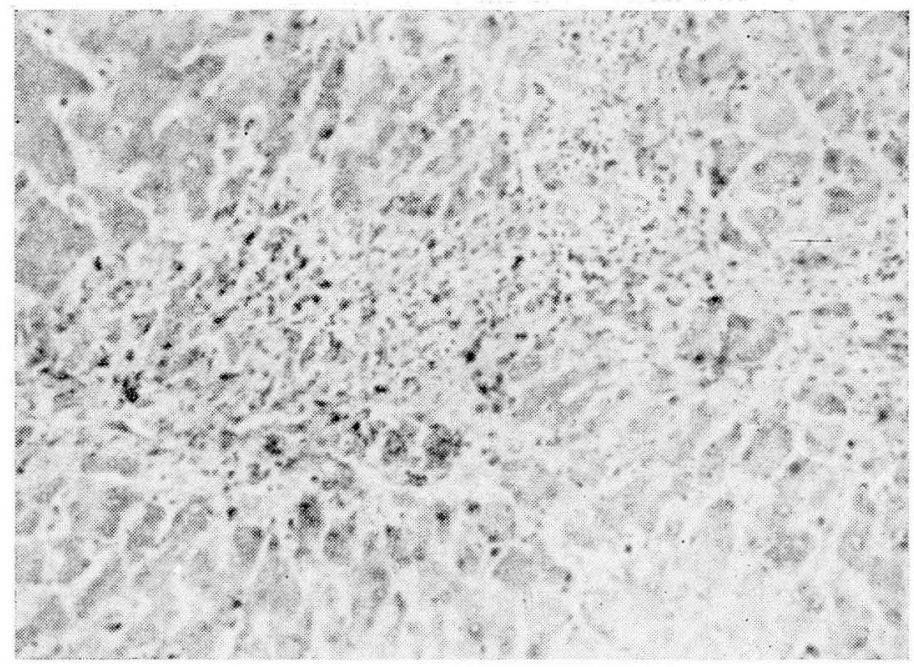

HIGADO.-Aspecto microscópico x 10. Necrosis perilobulillar con infiltrado leucocitario.

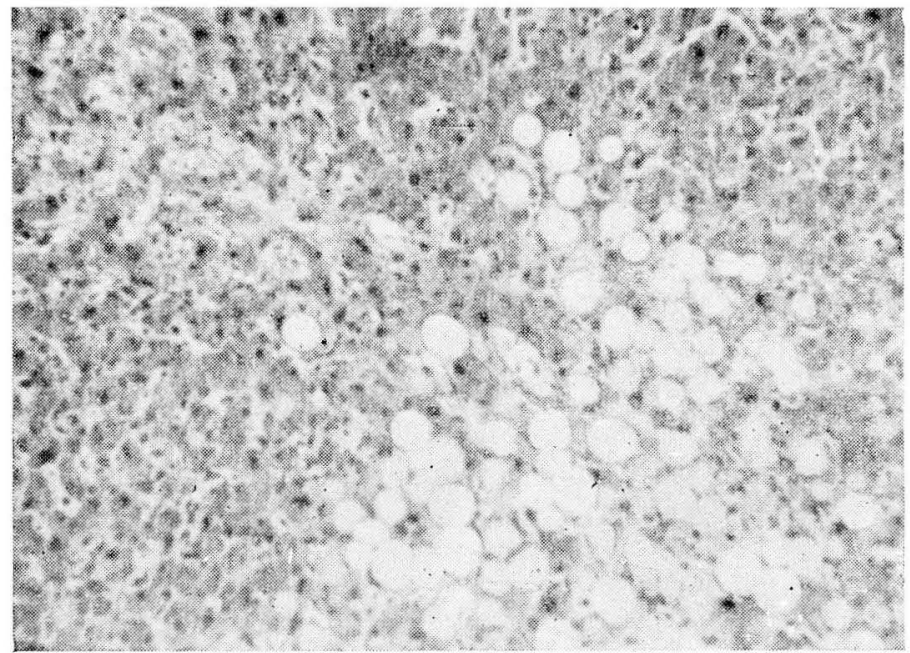

HIGADO.-Aspecto microscópico x 10. Degeneración grasa.

mann cree que debido a que la sangre se coagula en este sitio forma pequeños estancamientos o lagunas que son interpretadas co. mo ectasia capilar periportal. La sangre que comprime los sinusoides puede producir la necrosis de dos o más células hepáticas adyacentes. En pocos días el infiltrado de leucocitos polimorfo- 


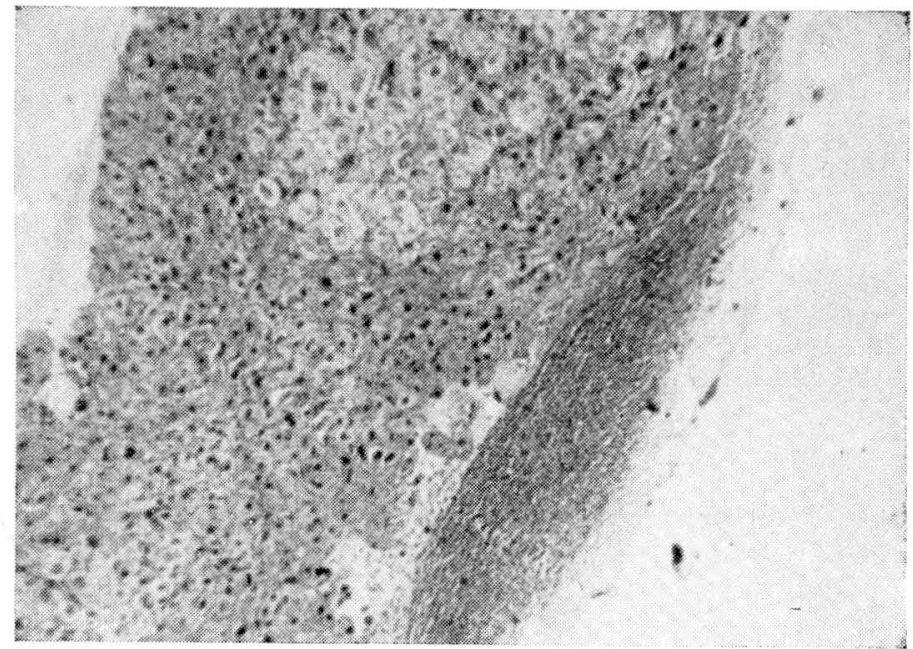

HIGADO.-Biopsia. Hemorragia, parece subcapsular. Hepatocitos aumentados de tamaño por depósitos de glicógeno.

nucleares es reemplazado por grandes mononucleares fagocitaxios y en corto tiempo la lesión ha desaparecido (A_56-1 y A_56-83).

Las lesiones difusas están caracterizadas por extravasación de plasma o sangre desde los sinusoides hacia la base de las coìumnas hepáticas. Según Dieckmann, no comprime las células y queda un canal que permite el flujo sanguíneo hacia la vena central del lobulillo.

Estas necrosis hemorrágicas han sido reproducidas por in. yecciones de fibrina (Dieckmann). Eppinger ha atribuído la rup. tura capilar a inflamación de la serosa basal.

También son frecuentes los cambios degenerativos del parénquima, tales como metamorfosis grasa, vacuolisación e infiltración leucocitaria, etc. (A-56_34, A-57-2iC4 y A-56-33).

\section{COMENTARIO}

El altísimo porcentaje de lesiones apreciables en hígados de toxémicas a simple vista, tales como las hemorragias subcapsures y el aspecto moteado grisoso, ha sido quizás la causa de que la mayoría de los investigadores hayan tratado de identificar lesiones microscópicas patognomónicas de toxemias en el hígado. Sinembargo ello no ha sido posible y actualmente ninguno de los actores más aceptados se atreve a sostener afirmaciones simila. 


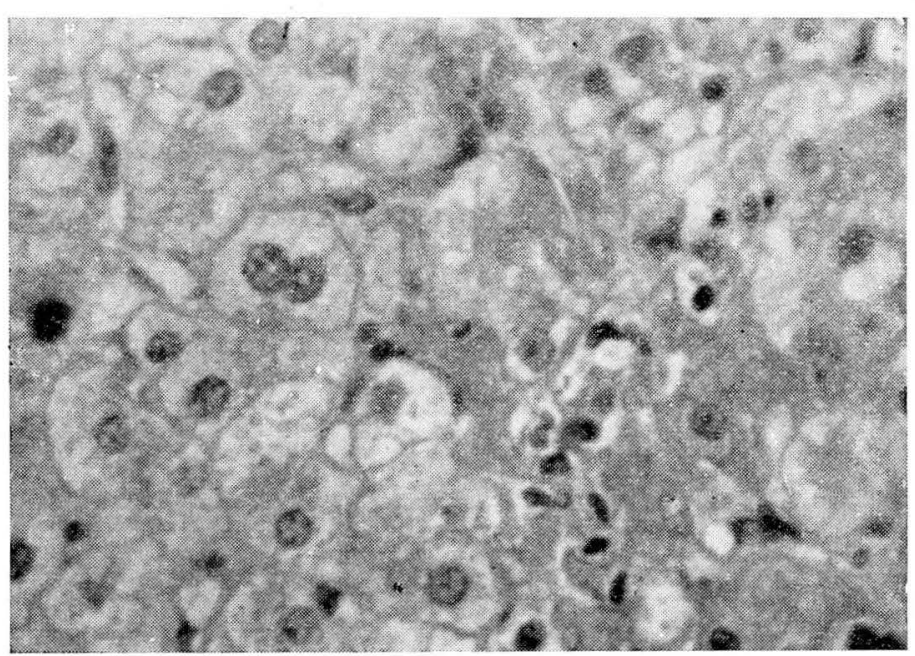

HIGADO.-Aspecto microscópico x 45. Seis a ocho días después del cuadro eclámptico. Cuandro regenerativo. Hepatocitos binucleados. Núcleos de diversos tamaños.

res, que sí fueron hechas al principio de las investigaciones. Las hemorragias periportales, "las necrosis hemorrágicas por ectasia y dilatación de los capilares alrededor del espacio portal bien sea que ocurran simultánea o sucesivamente" (Dieckmann) y los in. fartos anémicos, son algunas de las lesiones identificadas micros_ cópicamente en hígados de mujeres toxémicas, bien antes del parto aun en las primeras 24 horas del post_partum.

Microscópico.-En los casos estudiados todos han mostrado lesiones hepáticas distribuídas así:

Necrosis periportal hemorrágica y anémica en 4 casos.

Degeneración con necrosis centro-lobulillar en 1 caso.

Proceso regenerativo en 1 caso (A-57-180) en que la paciente murió 36 horas después del parto.

Abscesos gaseosos de hígado en un caso, provenientes de una toxémica muerta por gangrena gaseosa a partir de una endome. tritis.

Metamorfosis grasa del hígado en dos casos.

Trataremos este punto de patología en forma más extensa en el capítulo correspondiente a biopsias hepáticas cuando hagamos la correlación clínica entre la patología y las pruebas funcionales hepáticas. 


\section{PATOLOGIA DEL HIGADO}

\begin{tabular}{|c|c|c|c|c|c|c|c|c|c|}
\hline $\begin{array}{l}\text { No. de } \\
\text { Autopsia }\end{array}$ & $\begin{array}{l}\text { Diagnóstico } \\
\text { Toxemia }\end{array}$ & $\begin{array}{l}\text { Edad se } \\
\text { manas } \\
\text { Embar. }\end{array}$ & Alb. & $\begin{array}{l}\text { I n } \mathrm{g} \text { r e } \\
\text { Edema }\end{array}$ & T. A. & $\begin{array}{l}\text { Clase } \\
\text { Parto }\end{array}$ & Feto & $\begin{array}{l}\text { T. entre parto } \\
\text { o eclampsia } \\
\text { y autopsia }\end{array}$ & Cuadro Patológico \\
\hline A_57_124 & Pree_eclampsia leve & 40 & ++ & ++ & $145 / 80$ & Fórceps & $\mathrm{V}$ & Inmediata & $\begin{array}{l}\text { Congestión muy marcada. } \\
\text { Abundantes eosinófilos den- } \\
\text { tro de los vasos. Infiltración } \\
\text { grasa. }\end{array}$ \\
\hline A_57_180 & Pre_eclampsia severa & 32 & ++ & $+t$ & $180 / 110$ & $\begin{array}{l}\text { Cesárea } \\
\text { Abruptio }\end{array}$ & $\mathrm{M}$ & Siete dias & $\begin{array}{l}\text { Hepatocitos con dos núcleos } \\
\text { en vías de regeneración. Si_- } \\
\text { nusoides con leucocitos. }\end{array}$ \\
\hline A_57_204: & Pre_eclampsia severt & 40 & +++ & + & $200 / 120$ & Espont. & $\mathrm{V}$ & 24 horas & $\begin{array}{l}\text { Metamorfosis grasa alrede_ } \\
\text { dor espacios porta. Varios nú_ } \\
\text { cleos hepatocitos y citoplas_ } \\
\text { ma vacuolado. }\end{array}$ \\
\hline A_57_1 & Pre_eclampsia severa & 30 & $+t+t$ & + & $170 / 90$ & $\begin{array}{l}\text { Muerte } \\
\text { Intraut. }\end{array}$ & $\mathrm{M}$ & - & $\begin{array}{l}\text { Metamorfosis grasa perilo_ } \\
\text { bulillar focal. Necrosis perilo_ } \\
\text { bulillar. }\end{array}$ \\
\hline A_55_103 & Eclmpsia & 37 & - & +++ & $180 / 120$ & $\begin{array}{l}\text { Muerte } \\
\text { Intraut. }\end{array}$ & $\mathrm{M}$ & —. & $\begin{array}{l}\text { Necrosis periportal. Necro_ } \\
\text { sis izqumicas y hemorrágicas. } \\
\text { Dilatación espacios Diese. Zo. } \\
\text { nas degeneración grasa. }\end{array}$ \\
\hline A_56_34 & $\begin{array}{l}\text { Eclampsia } \\
\text { Abruptio Placentae }\end{array}$ & 36 & $+t+$ & $++t$ & $110 / 70$ & Espont. & $\mathrm{M}$ & - & $\begin{array}{l}\text { Necrosis perilobulillar. De- } \\
\text { generación turbia de las célu_ } \\
\text { las hep ticas. Esclerosis va- } \\
\text { sos. }\end{array}$ \\
\hline A_56_83 & Eclampsia & 38 & + & + & $200 / 120$ & $\begin{array}{l}\text { Cesárea } \\
\text { postmort. }\end{array}$ & $\mathrm{V}$ & $\longrightarrow$ & Necrosis perilobulillar. \\
\hline A.55.46i & Eclampsia & 30 & 一 & 一 & $180 / 100$ & $\begin{array}{l}\text { Muerte } \\
\text { Intraut }\end{array}$ & M & $\longrightarrow$ & Abcescs gaseosos del hígado. \\
\hline A_56_33 & $\begin{array}{l}\text { H. C. V. D. con pre_- } \\
\text { eclampsia sobreag. }\end{array}$ & 36 & $+t+$ & $++t$ & $260 / 160$ & Espont. & $\mathrm{M}$ & 24 horas & $\begin{array}{l}\text { Necrosis perilobulillar. } \mathrm{Zo}_{-} \\
\text {nas hemorrágicas. Abundante } \\
\text { infiltrado polimorfonuclear. }\end{array}$ \\
\hline A. 57.202 & $\begin{array}{l}\text { H. C. V. D. con pre_- } \\
\text { eclampsia sobreag. }\end{array}$ & 30 & $+t+$ & + & $280 / 150$ & $\begin{array}{l}\text { Muerte } \\
\text { Intraut. }\end{array}$ & M & $\longrightarrow$ & $\begin{array}{l}\text { Areas hemorrágicas. Zonas } \\
\text { destrucción centrolubulillar. }\end{array}$ \\
\hline
\end{tabular}




\section{R I $\tilde{\mathrm{N}} \mathrm{O} \mathrm{N}$}

Cambios macroscópicos.-Los cambios macroscópicos del ri_ ñón se caracterizan por hemorragias petequiales de pequeña o de gran área que se encontraron en muchos de nuestros casos, pero que no podemos concluir que sean constantes.

A los cortes el color del riñón es el de un gris blancuzco en casi todos los casos, excepto en uno que presentaba una coloración roja oscura que hacía dificil la demarcación de las áreas cor tical y medular. El pequeño hematoma perirenal que se halló en uno de los casos fue consecutivo a una biopsia renal que se prac. ticó cuatro días antes de la muerte de la paciente, fallecida por remorragia cerebral masiva.

El tamaño y peso fueron variables encontrándose cifras tota_ les entre los 180 y los 430 gramos de peso para los dos riñones.

Los hallazgos generalmente presentes en todo embarazo, tales como dilatación de las pelvis renales y ureteres, más notorios siempre al lado derecho, estuvieron presentes en todos nuestros casos.

Los cortes longitudinales mostraron macroscópicamente pali. dez tanto de la cortical como de la medular. En uno de los casos encontramos inversión de la relación del tamaño entre la cortical y la medular, siendo esta última mayor que la primera.

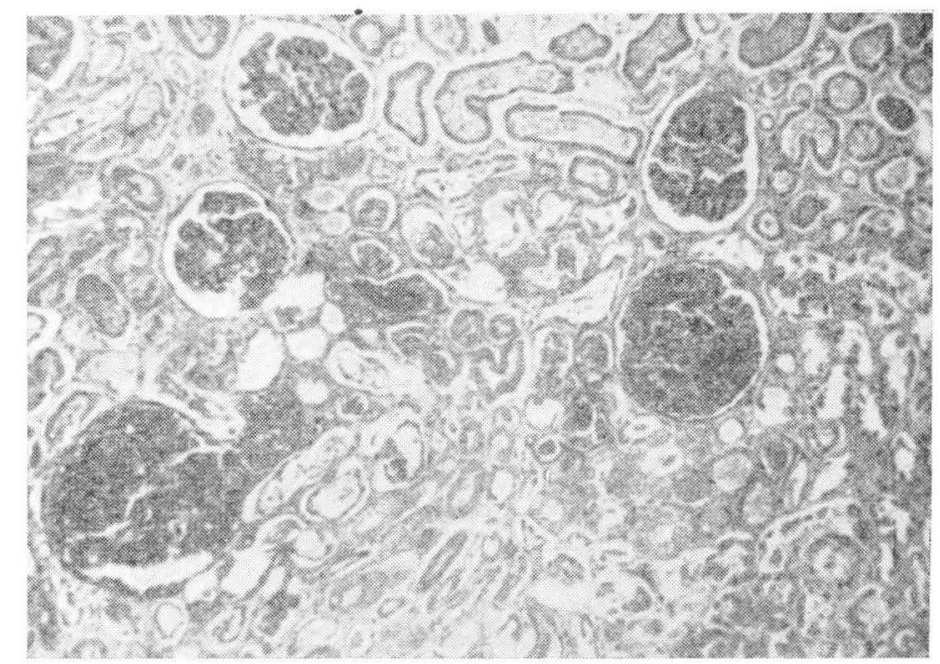

RIÑON.-Aspecto microscópico x 10. Disminución del espacio del glomérulo y la cápsula Bowman. ¿Necrosis hemorrágica glomerular? 
Aspecto microscópico.-De acuerdo con sus estudios sobre biopsias renales, Dieckmann ha catalogado sus hallazgos en tres grupos que resumen el grado de intensidad de los cambios histológicos encontrados.

\begin{tabular}{|c|c|c|}
\hline Grupo & Severidad & Lesiones Histológicas \\
\hline I & Severo $3+$ & $\begin{array}{l}\text { Marcada reducción de la luz capi- } \\
\text { lar asociada a engrosamiento de la } \\
\text { mebrana basal y a gran cantidad de } \\
\text { material fibrilar en el citoplasma. }\end{array}$ \\
\hline II & Moderado $2+$ & $\begin{array}{l}\text { Cambios similares a los anteriores } \\
\text { pero con una reducción menor de la } \\
\text { luz capilar. }\end{array}$ \\
\hline III & Leve $1+$ & $\begin{array}{l}\text { La membrana basal se halla engro- } \\
\text { sada ligeramente y se encuentran po- } \\
\text { cas fibrillas presentes en el citoplas- } \\
\text { ma. Los glomérulos están menos afec- } \\
\text { tados pero no se pueden considerar } \\
\text { normales. }\end{array}$ \\
\hline
\end{tabular}

Hemos creído conveniente transcribir este cuadro de Dieckman por pensar que es bastante didáctico y encierra el total de las principales lesiones microscópicas encontradas en nuestros casos.

Los cambios microscópicos fueron casi constantes y solamente en una de las autopsias no se identificó lesión renal.

Los cambios más constantes fueron los correspondientes a glomerulonefritis. En otros casos fueron de pielonefritis. Estos cam. bios de glomerulonefritis se caracterizaron por el engrosamiento de la cápsula de Bowmann, muy visible con la coloración de Schiff, engrosamiento que valió para que Allen le diera el nombre de' glomerulonefritis membranosa "más descriptivo, pero menos co_ nocido" (Page).

Este engrosamiento fue muy notorio en la mitad de los ca_ sos con la citada coloración de Schiff (A_55-103, A_57-202, A-56--34, A.56-1 y A-57-180).

Los cambios afectan a casi todos los glomérulos y son muy notorios mediante las coloraciones para tejido conjuntivo (P.A.S. y Schiff). Se aprecia así que la pared engrosada tiene un aspecto reticular, como perforado, a lo que Dieckmann ha llamado fibrilación de la membrana basal o reticulación del citoplasma (A_ 56_33). 


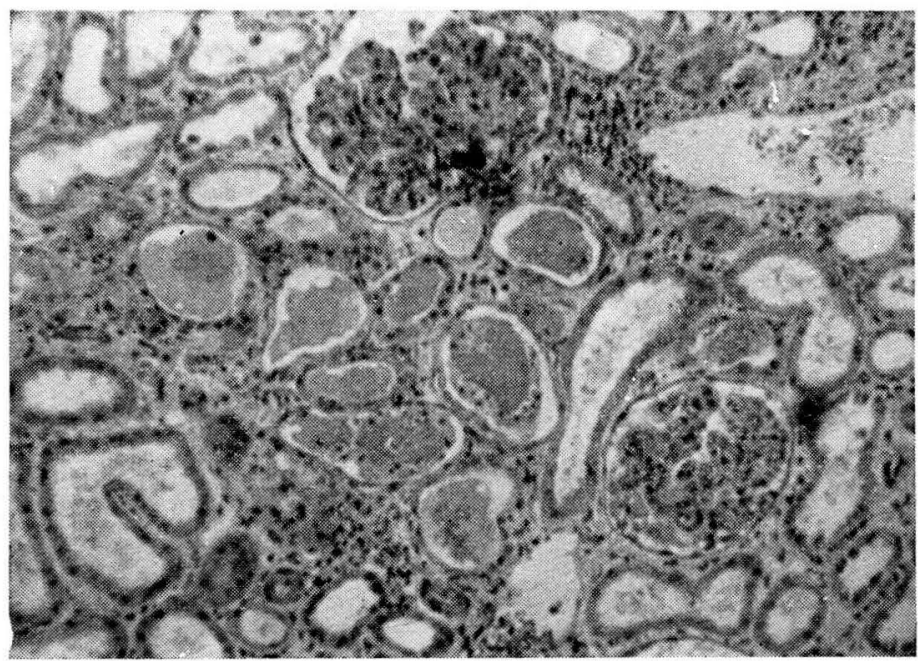

RIÑON.-Aspecto microscópico x 10. Infiltrado leucocitario. Cilindros hialinos.

El tamaño del glomérulo fue uno de los cambios más notorios, encontrándolo aumentado casi constantemente con la consiguien. te disminución del espacio entre éste y la cápsula (A-55_103, A-57 -202, A-56_33, A-57_180 y A_56_33). En algunas ocasiones del glo_ mérulo aumenta tanto su tamaño, que dá la apariencia de estar haciendo protrusión a través de la cápsula, fenómeno que se aprecíó mucho más nítidamente en los tejidos obtenidos por biopsia renal.

Aún no se ha dado una explicación muy clara al fenómeno de la disminución de la luz entre el glomérulo y la cápsula. Según Fahr los capilares glomerulares se edematizan en tal forma que llenan casi por completo la cápsula a pesar de que los vasos están €xangües.

Las paredes de los capilares están edematizadas y ensancha_ ras y en algunos casos los capilares están tan comprimidos que ios límites de las células no se pueden distinguir y los núcleos han desaparecido o por lo menos da esta sensación (Dieckmann).

En dos de nuestros casos se encontró franca degeneración hialina de los glomérulos de Malưhigio (A-55-103 y A.56-33), los que bien pudieran deberse a lesiones anteriores sin relación con la toxemia.

Son frecuentes las hemorragias peritubulares tanto de los co_ iectores proximales como distales (A_56_83 y A_56-33). 


\section{PATOLOGIA DEL RINNON}

\begin{tabular}{|c|c|c|c|c|c|c|c|c|}
\hline $\begin{array}{l}\text { Proto- } \\
\text { colo }\end{array}$ & $\begin{array}{l}\text { Viagnóstico Toxe- } \\
\text { mia Eclampsia }\end{array}$ & $\begin{array}{l}\text { Semanas } \\
\text { Edad }\end{array}$ & T. A. & $\begin{array}{l}\text { l } \mathrm{n} g \mathrm{res} \\
\text { Edemas }\end{array}$ & $\begin{array}{l}\text { so } \\
\text { Albúmina }\end{array}$ & $\begin{array}{cc}\text { Tipo de parto } & \text { Tie } \\
\text { y superviven }- & \text { par } \\
\text { cia fetal } & \text { psi }\end{array}$ & $\begin{array}{l}\text { empo entre } \\
\text { to y eclam- } \\
\text { a y autopsia }\end{array}$ & Cuadro patológico \\
\hline A.57_124: & Pre_eclampsia leve & 40 & $145 / 80$ & ++ & ++ & Fórceps_Vivo & $\begin{array}{ll}3 \mathrm{~h} . & \\
& \mathrm{n} \\
& \mathrm{s} \\
& \mathrm{A} \\
& \mathrm{a}\end{array}$ & $\begin{array}{l}\text { Glomerulonefritis aguda. Dismi- } \\
\text { nución del espacio capsular. Engro- } \\
\text { samiento de la membrana basal. } \\
\text { Aumento capa media de arterias y } \\
\text { arteriolas. }\end{array}$ \\
\hline A_56.1 & Pre.eclampsia severa & 30 & $170 / 90$ & + & $+++t$ & $\begin{array}{l}\text { No hubo. Muerte } \\
\text { Intrauterina. }\end{array}$ & $1 \frac{1}{1 / 2}$ h. $\quad \frac{b}{l}$ & $\begin{array}{l}\text { Glomerulitis membranosa. Trom- } \\
\text { bos hialinos de los capilares rena- } \\
\text { les. Petequias en la corteza de am- } \\
\text { bos riñones. }\end{array}$ \\
\hline A_57_80 & Pre_eclampsia severa & 32 & $180 / 110$ & ++ & ++ & $\begin{array}{l}\text { Cesárea abruptio. } \\
\text { Mi. Intrauterina }\end{array}$ & $2^{1 / 2} \mathrm{~h} . \quad \mathrm{e}$ & $\begin{array}{l}\text { Pielonefritis crónica. historia de } \\
\text { embarazo de } 2 \text { semanas y coma uré. } \\
\text { mico terminal. }\end{array}$ \\
\hline A_57_204 & Pre_eclampsia severa & 40 & $200 / 120$ & + & $++t$ & Espontanea. Vivo & 16 h. $45^{\prime}$ & No se evidencia patología. \\
\hline A. .55 .46 & Eclampsia & 30 & $180 / 100$ & - & - & $\begin{array}{l}\text { No hubc. Muerte } \\
\text { Intrauterina }\end{array}$ & $41 / 2$ h. $\frac{\mathrm{g}}{\mathrm{I}}$ & $\begin{array}{l}\text { Pielonefritis aguda bilateral con } \\
\text { gangrena gasecsa en riñón derecho. } \\
\text { Dilatación de los ureteres. }\end{array}$ \\
\hline A.55_.103 & Eclampsia & 37 & $180 / 120$ & +++ & $?$ & $\begin{array}{l}\text { No hubo. Muerte } \\
\text { Intrauterina }\end{array}$ & $6 \mathrm{~h} \cdot \quad \begin{array}{l}\mathrm{H} \\
\mathrm{h} \\
\mathrm{p}\end{array}$ & $\begin{array}{l}\text { Glomerulonefritis membranosa } \\
\text { Pielonefritis crónica. Degeneración } \\
\text { hialina de los corpusculos de Mal- } \\
\text { pigui. }\end{array}$ \\
\hline A_56_83 & Eclampsia & 38 & $200 / 120$ & + & + & $\begin{array}{l}\text { Cesárea post_- } \\
\text { mortem. Vivo }\end{array}$ & $10 \mathrm{~h}$ & Glomerulonefritis aguda. \\
\hline A_56_34 & $\begin{array}{l}\text { Eclampsia y Abrup. } \\
\text { tio Placentae }\end{array}$ & 36 & $\begin{array}{l}110 / 70 \\
250 / 140\end{array}$ & $+t+$ & $+t+$ & $\begin{array}{l}\text { Espont. Muerte } \\
\text { Intrauterina }\end{array}$ & $\begin{array}{lll}41 / 2 & h \cdot & d \\
& E \\
& c \\
& t \\
& l\end{array}$ & $\begin{array}{l}\text { Glomerulonefritis. Engrosamiento } \\
\text { de la basal y del endotelio capilar. } \\
\text { Esclerosis arterial y congestión vas } \\
\text { cular. Degeneración turbia células } \\
\text { tubulares con material amorfo en } \\
\text { los túbulos. }\end{array}$ \\
\hline A_56_33 & $\begin{array}{l}\text { H. C. V. D. con pre. } \\
\text { eclamp. sobre.ag. }\end{array}$ & 36 & $260 / 160$ & ++++ & +++ & $\begin{array}{l}\text { Espontánea. Muerte } \\
\text { Intrauterina }\end{array}$ & $6 \mathrm{~h} . \quad \mathrm{t}$ & $\begin{array}{l}\text { Nefrosis isquémica avanzada. } \mathrm{Pe} \text { - } \\
\text { tequias corticales renales. }\end{array}$ \\
\hline A_57_202 & $\begin{array}{l}\text { H. C. V. D. con Tox. } \\
\text { sobre.agregada }\end{array}$ & 30 & $280 / 150$ & + & $++t$ & $\begin{array}{l}\text { No hubo. NEuerte } \\
\text { Intrauterina }\end{array}$ & $6 \mathrm{~h} . \quad \begin{array}{r}\mathrm{r} \\
\mathrm{d} \\
\\
\\
\\
\mathrm{ll} \\
\mathrm{r}\end{array}$ & $\begin{array}{l}\text { Glomerulonefritis aguda. Glomé- } \\
\text { rulos aumentados y engrosamiento } \\
\text { de la basal de los capilares. Célu- } \\
\text { las inflamatorias. Areas de hemo- } \\
\text { rragia reciente y antigua. }\end{array}$ \\
\hline
\end{tabular}




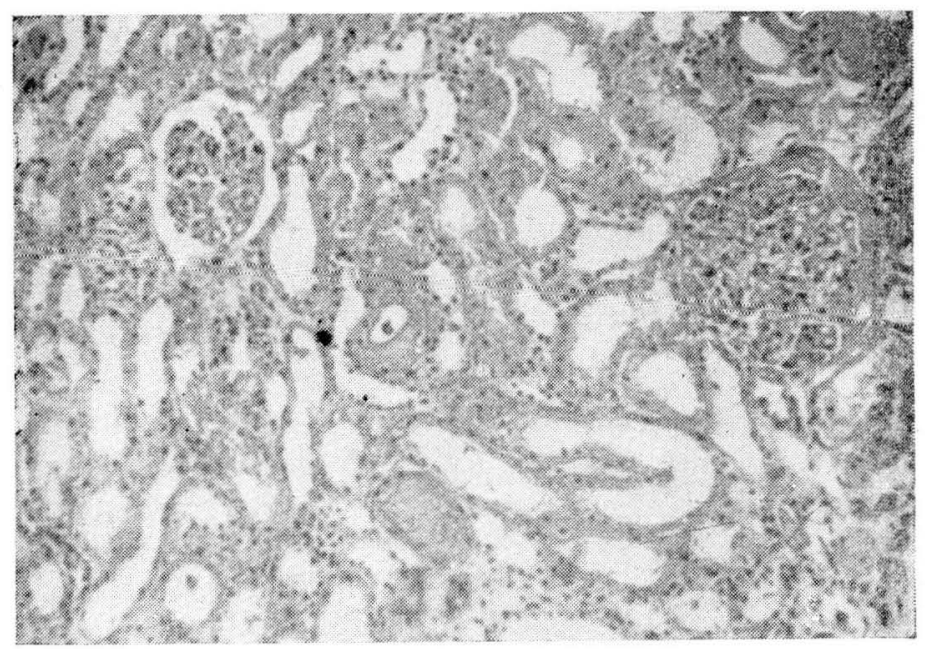

RIÑON.-Aspecto microscópico x 10. Cilindros hiəlinos. Infiltrado albuminoso de la cápsula de Bowman.

En un caso la ruptura de los túbulos con necrosis peritubular (A-56-33) estuvo acompañada de vacuolización del epitelio de los túbulos proximales. Parece ser que los cambios de aspecto albu. minoso sean debidos a la reabsorción de proteínas del filtrado glomerular y así tendrían la misma explicación que los cambios encontrados en otras afecciones renales.

La presencia de cilindros granulosos hematíes y glóbulos grasos en los túbulos proximales y distales, fue frecuente (A.55-103 y A-56_33).

La explicación de estos cilindros es bien conocida: la proteína que no alcanza a ser absorbicla y que está contenida en el flujo tubular es llevada a los túbulos distales y colectores donde se coagula al encontrar condiciones que la hacen menos soluble. Esta coagulación se hace bajo la forma de cilindros hialinos tubulares. Pero si la proteina al coagularse envuelve otras sustancias o he. moglobina o células de los mismos túbulos, forma entonces los ci. lindros granulosos y epiteliales que al pasar a la orina vesical in. dican que hubo un momento en que las proteínas filtradas axcedieron la capacidad reabsorbente de los túbulos. Es decir, hubo un franco compromiso de la función tubular.

Los trombos hialinos o de fibrina en los capilares y la degeneración fibrinoide capilar se encontraron en varios casos (A.56-1 y A-55-103). Los cambios sobre los vasos renales se encontraron 
presentes bajo la forma de engrosamiento de la membrana basal y del endotelio capilar, así como esclerosis y congestión (A-57_202 y A_56-34). El engrosamiento en uno de los casos fue tan marcado que condujo a la casi obliteración del vaso.

En las lesiones renales severas se observandep ósitos de fibri_ na, en algunos de los pequeños vasos y cambios degenerativos agudos en las arteriolas, siendo las aferentes las que se encuentran más engrosadas y dilatadas.

De lo dicho hasta aquí en relación con la patología renal pa_ rece comprobarse la teoría de que las lesiones de la toxemia severa tienen su asiento en una lesión diseminada de los pequeños vasos y capilares que lleva secundariamente a las lesiones parenquimatosas.

Queremos finalizar mencionando un caso en el que debido a una endometritis consecutiva a ruptura prematura de membranas, la paciente falleció por gangrena gaseosa cuyos focas fueron más notorios en el riñón derecho.

El cuadro siguiente es un resumen y una correlación entre el điagnóstico de la toxemia, la edad del embarazo, la hipertensión, los edemas y la abuminuria, con las lesiones patológicas.

\section{PATOLOGIA DEL CEREBRO}

La mayoría de los patólogos, con ligeras diferencias, están de acuerdo sobre el alto porcentaje de lesiones cerebrales encontra_ das en las toxemias.

Los principales hallazgos se pueden caracterizar por edema y hemorragia y aun en los casos de ausencia de edema, no se des. carta la posibilidad de cambios anormales intra y extra_celulares en el balance del agua y los electrolitos. Zangeweister (1919) y Fisher (1921) atribuyeron al edema cerebral la causa de las convulsiones.

Creen que deben ser practicados estudios más serios y que el demasiado tiempo transcurrido entre la muerte y la autopsia sea una de las causas de los cambios autolíticos encontrados. Que el cerebro debe ser pesado y disecado cuidadosamente, debido a que una gran mayoria de cerebros de toxemias son francamente edematosos. Recomienda observar las membranas, y cuando se las encuentre húmedas y las circunvoluciones cerebrales aplanadas o no claramente definidas es presumible que el cerebro esté edematoso. Se puede confirmar practicando un corte con un bisturí, lo cual nos da un aspecto típico. 


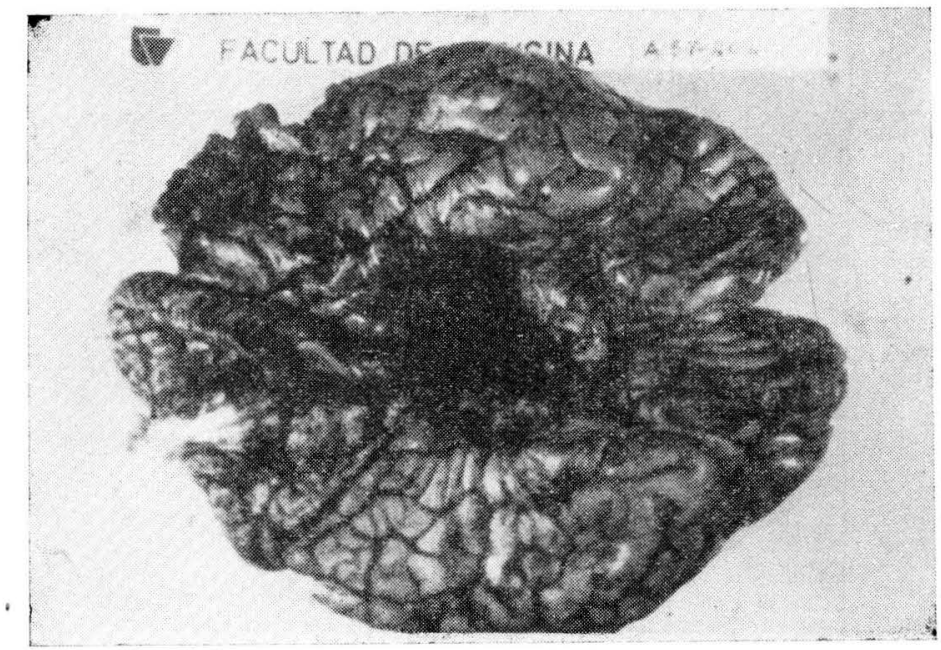

CEREBRO.-Aspecto macroscópico. Hemorragia intracerebral con destrucción del piso del tercer ventrículo.

Aspecto macroscópico.-Schmorl (1893) fue el primero en ad. vertir la asociación entre la eclampsia y el punteado hemorrági. co en todos los órganos.

Frecuentemente se encuentran hemorragias macroscópicas (A_57_204), reblandecimientos (A-55-40) y hemorragias meningeas (A_57-202, A-56_33 y A-56-34).

En los casos en que se pesaron los cerebros fluctuaron entre 950 a 1.500 gramos.

Sheehan encontró las lesiones macroscópicas en los casos de verdadera eclampisia en un $45 \%$ lo que concuerda con nuestros hallazgos.

Las hemorragias subcorticales, para Sheehan, son secundavias al gran trastorno vasomotor en los vasos cerebrales, y por elsto que la recuperación de la eclampsia es completa desde el pun. to de vista neurológico.

En un caso (A-57-204) que presentó una intensa crisis de cianosis es posible pensar que hubiera inicialmente hecho una hemo. rragia pontina, aunque el cuadro final fue de edema agudo pulmonar debido a depresión circulatoria por hemorragia cerebral.

Sheehan establece que $1 / 3$ parte de las hemorragias son ma_ croscópicas y $2 / 3$ son microscópicas. Nosotros encontramos en 4 casos signos macroscópicos de hemorragia, y en 5 hemorragias microscópicas. Las localiza en tres áreas: 


\section{PATOLOGIA DEL CEREBRO}

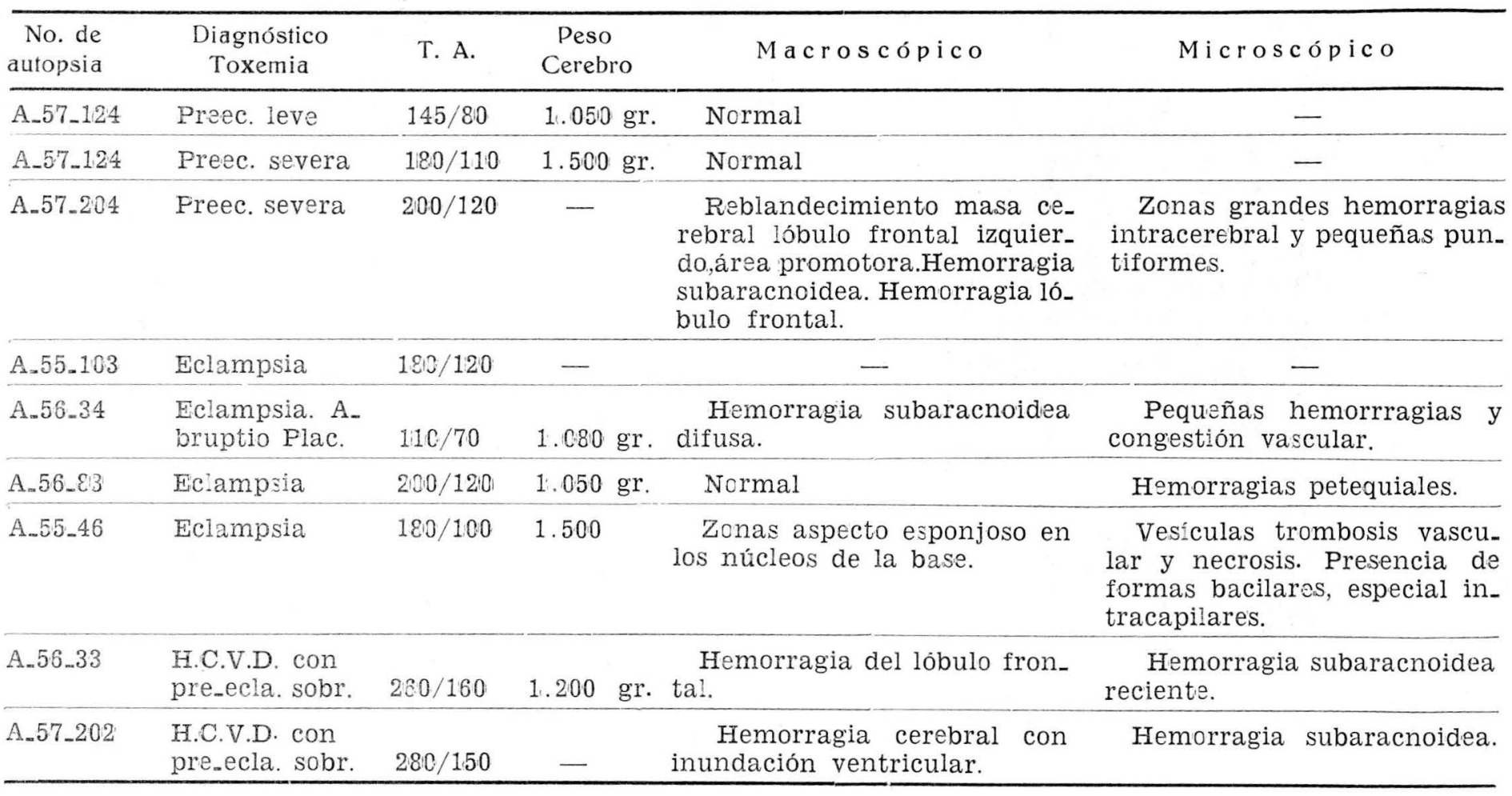




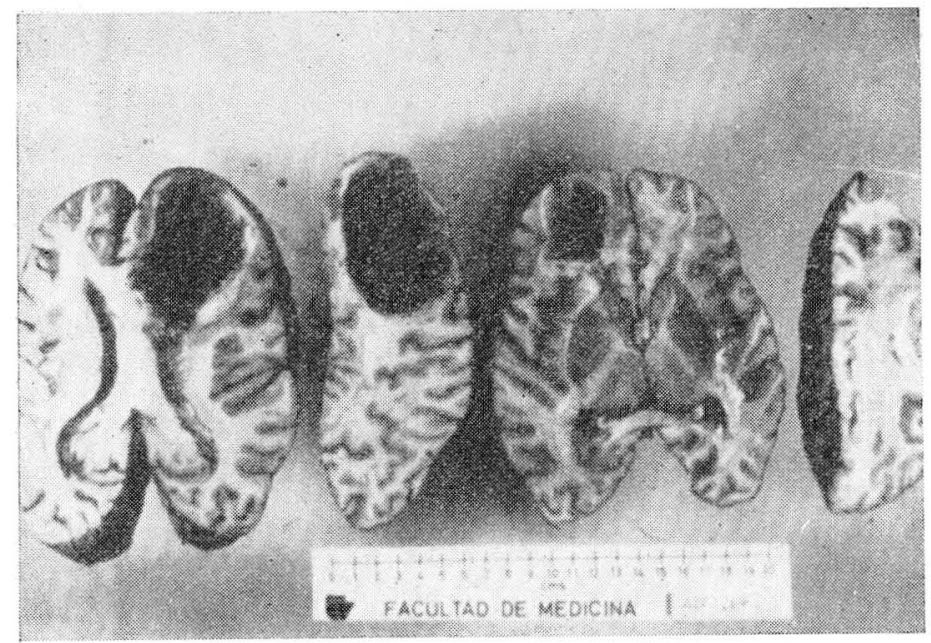

CEREBRO.-Aspecto microscópico x 45. Hemorragias petequiales intracerebrales.

1) Pontinas que son de varios tamaños y cuando son grandes se rompen dentro del cuarto ventrículo (A_57-204).

2) En los ganglios basales, que se pueden establecer en los núcleos caudados, atrás del tálamo.

3) Lesiones corticales.

Las pacientes con necrosis cortical renal pueden tener convulsiones y morir en coma. Presentan ablandamientos del cerebro. Tenemos el caso A_55_46 que presentó lesión gangrenosa renal. En el cerebro macroscópicamente encontramos zonas de aspecto esponjoso en los núcleos de la base (A-55-46).

Martín y Sheehan han descrito trombosis de las venas cere. brales que producen ablandamiento y hemorragia (A-55-46).

\section{ASPECTO MICROSCOPICO}

El cuadro microscópico por lo general es un fiel reflejo de los hallazgos macroscópicos puesto que en la sustancia gris de la corteza aparecen los cambios histológicos propios de los reblandecimientos cerebrales. Por otra parte las hemorragias petequiales múltiples son la manifestación externa de las trombosis y ruptu_ ras de los pequeños vasos cerebrales y aun de los grandes, pues. to que a pesar de que la toxemia se encuentra en un alto porcentaje en mujeres jóvenes, no es raro ver en los casos de eclamp- 


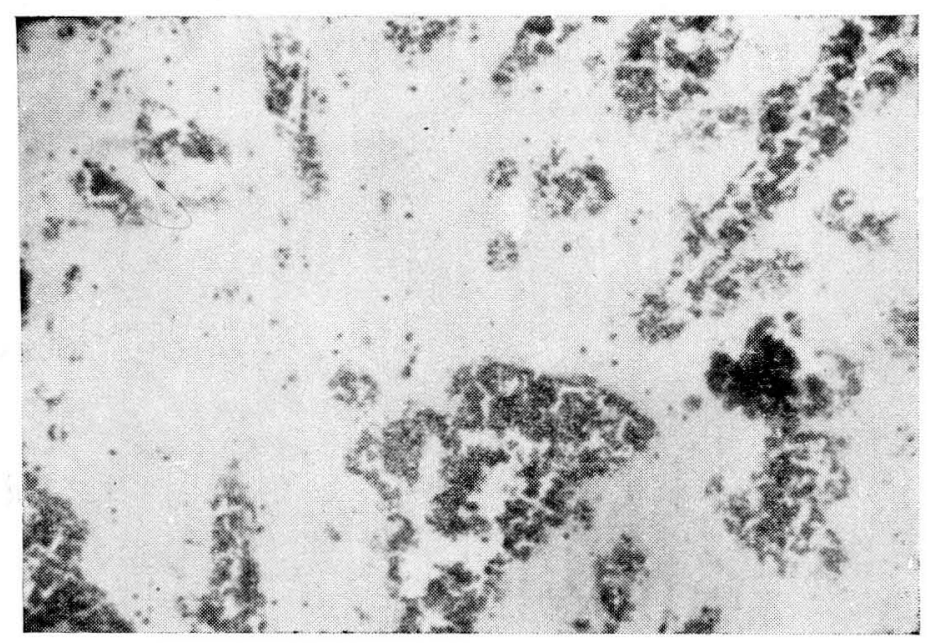

CEREBRO.-Aspecto macroscópico. Hemorragia intracerebral.

sia fatal la ruptura de un vaso intracraneal que va a producir una verdadera inundación cerebral. En los mismos vasos se observan frecuentemente cambios arterioescleróticos agudos con trombosis, depósitos de fibrina y pequeñas hemorragias perifocales, según las observaciones de Sioli citado por Page.

En el caso A.55-46 de nuestra serie, al lado de las vesículais propias del cuadro de gangrena gaseosa diseminada encontramos las lesiones cerebrales tan frecuentemente asociadas a los cuadros de toxemia como son la trombosis vascular y la necrosis peri. vascular.

\section{PATOLOGIA DE PULMON}

No ha sido posible hallar, por ninguno de los autores, patología pulmonar propia de la toxemia. Sinembargo la incidencia de afecciones pulmonares concomitantes es enormemente alta. En los casos revisados por nosotros hemos encontrado cinco casos de muerte por edema pulmonar agudo y uno por atelectasia pulmo_ nar como complicación anestésica en una toxémica. Dada la alta cifra de complicaciones pulmonares (edemas, congestiones, bronconeumonía, etc.), debemos pensar que lógicamente el tratamien. to en una toxémica debe incluír como punto básico la prevención y tratamiento de estas complicaciones. Ello es tanto más importante cuanto que si consideramos que la causa de muerte de hijos de toxémicas es en su gran mayoría la anoxia fetal por le_ 


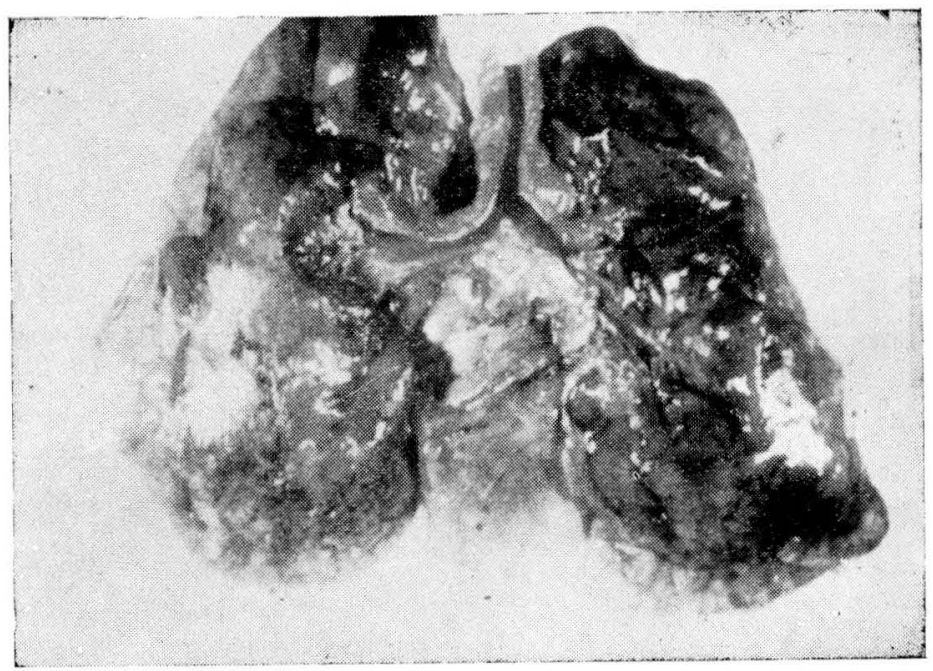

PULMON.-Aspecto macroscópico. Hemorragia.

siones placentarias y circulatorias, se va a agregar a ellas la anoxia producida por las afecciones pulmonares de la madre toxémica.

Estos hallazgos nos inducen a pensar que quizás en el trata_ miento actual de la toxemia estemos incluyendo factores que contribuyan a una depresión respiratoria que sumada a la anoxia de la toxemia, a la posición permanente de decúbito de la paciente sedada, al espasmo vascular, a la insuficiencia circulatoria a la sobrecarga cardíaca y al colapso vascular, facilitan el progreso de las afecciones y otros cuadros congestivos pulmonares letales De las diez autopsias que presentamos, en nueve encontramos lesiones pulmonares. La restante fue una autopsia que se limitó a órganos abdominales y por ello no podemos incluirla en esta parte de nuestro estudio. Por lo mismo podemos concluír que se encontró lesión pulmonar en todos los casos presentados, en los cuales la lesión pulmonar si no fue la causa inmediata de la muerte, por lo me. nos fue un factor coadyuvante de importancia.

Los cuadros pulmonares comprobados por patología, son los siguientes:

A-55-46. -Congestión y edema pulmonar. Bronconeumonía de los lóbulos de ambos pulmones. Trombosis vascular.

A-56_1.-Congestión y edema pulmonar. Atelectasia focal. Derrame pleural bilateral (2:000 c.c. en un lado y 500 c.c. en el otro).

A_56-33.-Congestión y edema pulmonar. Atelectasia focal. Derrame pleural. Bronconeumonía. 


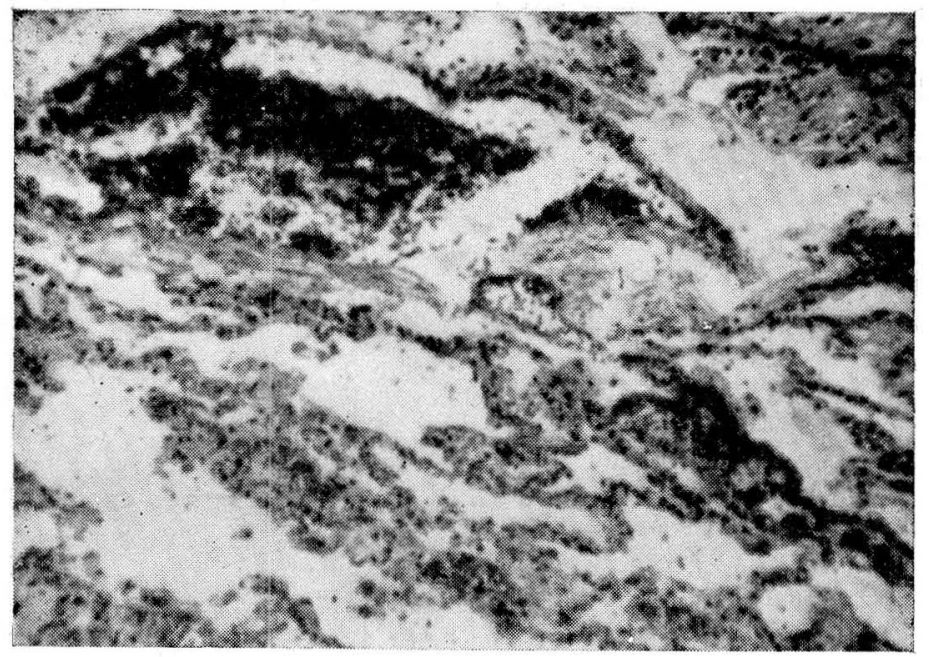

PULMON.-Aspecto microscópico x 45. Hemorragia y congestión.

A-56_34.-Enfisema pulmonar. Bronconeumonía.

A_56-83.-Congestión y edema pulmonar.

A-57_180.-Congestión y edema pulmonar. Bronconeumonía pulmón izquierdo.

A-57-202.-Congestión y edema pulmonar. Enfisema periférico.

A_57-204.-Edema pulmonar. Destrucción de séptum. Hemorragia. Ingurgitación sanguínea.

Los hallazgos que presentamos están de acuerdo con los de Dieckmann aun cuando es de anotar que en nuestros casos han sido del 100\%. En resumen: Se encontró edema y congestión. In. fección sobre_agregada en gran cantidad de casos. Derrame pleural en dos.

\section{PATOLOGIA DEL CORAZON Y AORTA}

En casi todos los casos estudiados hemos encontrado hemorragias, equimosis petequias y pequeñas zonas de necrosis cardía_ cas, lo que estaría de acuerdo con los hallazgos citados por Dieckmann quien encuentra estas lesiones en un 40 a $60 \%$ de sus casos.

Nos ha sorprendido la alta incidencia de lesiones aórticas y valvulares encontradas en casi todos los casos estudiados. Este gran número no se encuentra en relación con los promedios descritos hasta el momento en la bibliografía que hemos consulta. đo. Se encontró esclerosis de las válvulas aórtica y mitral en tres 
de los casos (A_56-83, A-57-124 y A-57_202). Esclerosis y ateroma_ tosis de la aorta en 7 de los casos, en uno de ellos (A-56_83) acompañado de esclerosis de las coronarias. Hipertrofia y dilatación cardíaca se encontró también en varios de los casos (A_56_1; A-57202 y A-57_204). En uno de los casos (A_56_1) cuya posible causa de muerte fue una insuficiencia cardíaca aguda, se encontró un derrame pericárdico y pleural de 500 c. c. y en otro ((A.56-33) de 35 c. c.

Según reciente comunicación preliminar de las investigacio_ res que en la actualidad se adelantan sobre arterioesclerosis en el Departamento de Patología de la Facultad de Medicina del Valle, los doctores Restrepo y Mc Gill suministraron el dato de que han encontrado una mayor incidencia de ateromatosis en muje. res que en hombres y que dicha lesión es aún más frecuente en pacientes embarazadas.

Creemos también que este hallazgo nos explicaría la alta in. cidencia de muerte por insuficiencia ventricular derecha (edema pulmonar).

Anotamos igualmente que fue muy alta la frecuencia de hemorragias tanto petequiales y equimóticas como endo-pericárdicas y pericárdicas y en uno de los casos se encontró una gran equímosis subendocárdica de la aurícula derecha (A_57-46).

\section{PATOLOGIA DE SUPRARRENALES}

En nuestros casos encontramos necrosis y hemorragia (A-5633) y (A-56_34), con hiperplasia nodular de la corteza suprarrenal.

Dodds atribuye estas lesiones a dieta baja en proteínas, a la toxemia leve y posiblemente al Tricloro Etileno (Trilene) usado como anestesia.

Es muy difícil poder analizar los hallazgos de las suprarre. nales debido a que si la autopsia no es practicada dentro de la primer hora post-mortem o si el cadáver no es convenientemente conservado en frío se producen cambios por verdadera lisis cada. vérica que dificultan o imposibilitan el diagnóstico de la lesión.

Consideramos que debe darse al estudio histológico e histoquímico de las suprarrenales una mayor importancia en relación con la toxemia del embarazo puesto que el trastorno del metabolismo del sodio y del potasio en las pacientes toxémicas y la gran incidencia del colapso vasomotor parecen indicarnos el importante papel de las suprarrenales en este síndrome. 


\section{B A Z O}

Los cambios que afectan el bazo son los mismos que han sido observados en general en la patología de las toxemias, como son las lesiones vasculares y hemorragias. Se pueden resumir como zonas de necrosis y grandes infartos.

Macroscópicamente hemos comprobado congestión y friabili_ dad del tejido (A-57-202, A-56_34, A-57-204, etc.) en la mayoría de los casos.

Aspecto microscópico.-En general encontramos un cuadro de hemorragia en la mayoría de nuestros casos (A_57-202).

En uno de los casos la pulpa blanca había casi desapareci. do dejando pequeñas formaciones que pudieran ser los vestigios de los corpúsculos de Malphigi (A-57_204).

Los cambios vasculares se tradujeron en hipertrofia de las paredes de los vasos (A_57-204, A_56-83 y A-57-202) y en otros había un cuadro de esclerosis sobre-agregado (A-56-34).

La sustancia hialina identificable en la mayoría de las toxémicas, se presentó en los corpúsculos como consecuencia de ne. crosis hialina de éstos, dando también engrosamiento e hialinización de las arteriolas de los mismos. (A-56-33 y A_55-103).

\section{H I P O F I S I S}

Las relaciones de la pituitaria con la patología y fisiopatología de las toxemias son un tema de amplias investigaciones.

La glándula sufre cambios histológicos durante el embarazo, apareciendo aumentada de tamaño sobre todo de su lóbulo an. terior.

Nuestras observaciones estuvieron limitadas a 3 casos, en los cuales solamente encontramos los cambios típicos del embarazo (A-56_83, A-57-124 y A-56_34).

\section{UTERO Y PLACENTA}

Las lesiones uterinas se caracterizan por hemorragias subse_ rosas que de acuerdo con la intensidad de la toxemia y sobre to. do en los casos de abruptio llega hasta constituir el cuadro de apoplejía útero-placentaria.

La patología tanto placentaria como del útero, se halla des. crita detenidamente en el capítulo sobre "Abruptio Placentae". 


\section{PATOLOGIA DEL OVARIO}

No hemos encontrado descritas lesiones patológicas típicas en los ovarios de pacientes toxémicas. En dos de nuestros casos hallamos lesiones vasculares consistentes en proliferación de las capas arteriales que en uno de ellos llega casi a obstruir la luz de la arteriola (A-56_34). La congestión vascular y la hiperplasia del estroma, presentes en casi todos los casos, parecen ser cam. bios propios del embarazo.

\section{PATOLOGIA DE VEJIGA URINARIA}

Los cambios fueron muy poco notorios y fácilmente explicables no solamente por el embarazo sino por las pequeñas inflamaciones banales frecuentes en este estado. Dichos cambios consistieron en áreas hemorrágicas con ifiltrado de mononucleares y edema de la mucosa.

\section{PATOLOGIA DEL PANCREAS}

Un cambio constante fue la autolisis. Algunos presentaron fenómenos vasculares de tipo escleroso.

\section{PATOLOGIA DE LA GLANDULA TIROIDES}

Los folículos se presentaron siempre llenos de sustancia coloide aumentada, como es lo normal, durante el embarazo. No en. contramos cambios patológicos especiales.

\section{DEMAS ORGANOS}

Se estudiaron glándula mamaria, linfáticos, estómago, esófa_ go e intestino sin apreciar cambios especiales.

\section{COMENTARIO FINAL}

Se presentan diez exámenes post-mortem en pacientes que se clasificaron dentro del síndrome de pre_eclampsia-eclampsia. Los principales hallazgos patológicos de nuestros casos se encontra. ron en hígado, riñón, cerebro, aorta y pulmón.

En todas las autopsias se encontraron lesiones patológicas en el hígado: necrosis peri-lobulillar y metamorfosis grasa, como tam. bién la notoria capacidad de regeneración de la célula hepática 
con la consecuente regresión de las lesiones atribuibles a la toxemia.

En la mayoría de nuestros casos se encontró lesión renal manifestada por congestión glomerular, disminución del espacio entre el glomérulo y la cápsula, lesiones vasculares de los capilares y trombos hialinos o granulosos intra_tubulares.

Se presentaron en varios casos hemorragias cerebrales variables en extensión y localización y con intensidad desde el punteado hemorrágico hasta la inundación ventricular.

Hemos encontrado una alta incidencia de lesiones esclerosas y ateromatosas de la aorta. Sería conveniente buscar la relación entre estos hallazgos y la toxemia.

La frecuencia con que en nuestros casos estuvieron presentes las lesiones pulmonares nos hace considerar la necesidad de pre. venir estos accidentes durante el tratamiento de las pacientes toxémicas.

Las lesiones patológicas de útero y placenta se encuentran estudiadas dentro de los apartes correspon'dientes a patología placentaria y abruptio placentaie.

Queremos mencionar la importancia de la correlación clínicopatológica como base de los estudios sobre toxemias. Es del ma_ yor interés solicitar a los patólogos de todo el país que concedan al problema de la toxemia la trascendencia que realmente tiene, para poder llegar a conclusiones propias en nuestro medio que es tan diferente por muchos aspectos (nutricional, ambiental, etc.), de los medios en que se han adelantado los trabajos que usualmente nos sirven como puntos de comparación. Creemos que en cualquier sitio en que esta solicitud se haga se encontrarán los mismos intereses y apoyo que nos ofreció el Departamento de Patología de la Facultad de Medicina de la Universidad del Valle.

\section{PATOLOGIA DE HIJOS DE TOXEMICAS}

Así como consideramos grave el problema de la toxemia para la madre, ảebemos considerarlo aún más grave para el feto.

La mayoría de los investigadores están de acuerdo en consi_ cerar que un $40 \%$ de los hijos de toxémicas mueren poco antes del parto o durante él. Las estadísticas del Margaret Hague Maternity Hospital, citadas por Greenhill, asignan un 33\% de mortalidad a los fetos de toxémicas y consideran que la aparición de 
albuminuria en una paciente con enfermedad cardio-vascular hi. pertensiva es siempre seria para el feto.

Se ha establecido que por fortuna la toxemia no parece dejar secuelas en los niños y Browne tiene interesantes observaciones al respecto en hijos de madres toxémicas que han sido controlados por él hasta 13 años después de nacidos.

El compromiso vascular materno durante la toxemia se manifiesta intensamente en la circulación placentarı y como conseeuencia, el aflujo sanguíneo al feto se hace insuficiente para su crecimiento y desarrollo obteniéndose por lo general fetos madu_ ros en edad pero no en talla, en los casos leves. Cuando la suplencja sanguínea está disminuída considerablemente, los elementos metabólicos requeridos para la vida están mermados y el aumen. to en los productos de desecho puede llegar a ser incompatible con la vida fetal, resultando así la muerte intra_uterina.

De entre las manifestaciones toxémicas maternas, la hipertensión y la albuminuria han sido tomadas como base de pronósticos sobre la supervivencia fetal. Así, algunos autores consideran que la gravedad del pronóstico está en razón directa con la albuminuria. Browne se basa en la hipertensión para el pronósti. co fetal en los casos de enfermedad cardio-vascular hipertensi_ va con toxemia sobre_agregada y dice que "en cualquier caso en que la presión sanguínea no baje en el segundo trimestre del embarazo, el feto muere in_útero. No sucede lo mismo si esta baja tensional se produce en esa época de la gestación, caso en el cual se obtienen fetos vivos".

En todos los casos de muerte fetal se ha encontrado como causa directa la anoxia intra-uterina y la inmadurez del aparato res_ piratorio, atribuibles no solamente al hecho de que por lo general los partos se producen prematuramente, sino al problema vas. cular mismo. La anoxia se manifiesta por hemorragias cerebrales y pulmonares de variada intensidad. Debe mencionarse la diferen. cia entre la hemorragia subserosa que es propia de los traumatismos durante el parto, de la hemorragia cerebral de localización profunda que es propia de la anoxia. Por eso es obvio pensar cómo se ensombrece el pronóstico fetal si a la toxemia se agrega un parto distócico.

En esta contribución al problema de la toxemia presentamos cinco autopsias de hijos de madres toxémicas. En la mayoría se observaron las hemorragias cerebrales y pulmonares ya mencio- 
nadas, no solamente en los nacidos vivos sino en los casos de muerte intra.uterina.

En uno de los casos (A_55-8) llama la atención la madurez avanzada de los genitales. Es el caso de una niña hija de madre toxémica, nacida viva a término, pero que sobrevivió solamente 10 minutos. Los ovarios tenían una activa maduración folicular semejante a la que se encuentra en la mujer en el estado puberal. Las trompas presentaban las características del órgano adulto, llegando las fimbrias hasta la parte central del tubo y con gran hiperplasia del epitelio. En vagina se encontró el epitelio poliestratificado propio de la mujer adulta y en el endocérvix gran hi_ perplasia glandular.

Cambios similares, aun cuando menos avanzados, se observaron en otros fetos femeninos.

Estos cambios son atribuíbles a los altos niveles de gonadotrofinas maternas presentes en la toxemia y cuya cantidad parece estar de acuerdo con la intensidad del síndrome.

En los fetos masculinos parece reflejarse esta acción sobre las células de Leydig del testículo que en todos los casos mostra_ yon gran hiperplasia.

El resumen de los hallazgos patológicos en fetos de madres toxémicas y su correlación con la edad del embarazo, el tipo de toxemia y el tipo de parto, los presentamos en el cuadro siguiente.

\section{BIBLIOGRAFIA}

ALLEN. A. C.-The Kidney Grime and Straton. New York, 1951.

BARTHOLOMEW, R. A. and COLVIN, B. D.-Diagnosis of the ocurrence of toxemia of pregnancy by examinacion of the unknown placenta. Am. J. Obst_Gynec. 36:909. 1938.

CORREA PELAYO.-Patología de las Toxemias, 1955. Cali. En Prensa. The Ciba Collection of Medical Ilustrations. Vol. 2. Reproduction. Sepstein 1954.

DIECKMANN, W. J.-The toxemias of pregnancy. 2nd edition. St. Louis Mosby, 1952.

DIECKMANN W. J.-Potter E. L. Mc Cartney C. Am. J. Obs_Gyn. 73: $1,1957$.

DI FIORE MARIANO S. U.-Diagnostico Histologico $3^{\text {a }}$ Ed. Bs. As. El Ateneo, 1951. 
FORBUS, W. D.-Reaction to injury. Vol. II: Baltimore. William and Wilkins Co., 1950.

LEUNEY and PARKER.-Placenta in toxemia of Pregnancy. Am. J. Obst. Gynec. 39: 1000,1940.

MUÑ̃Z, S.-Complicaciones de las Toxemias. Cali, 1956. En prensa.

PAGE E. W.-The Hipertensive Disorders of Pregnancy. Spingfield III. Ch. C. Thomas, 1953.

La Placenta humana. Reimpreso de Abbotterapia. 151, 1955.

GREEP R.O.-Histology. Toronto N. Y. The Blakiston Company, Inc., 1954.

TATUM H. J.-(Comunicación personal).

THEOBALD G. W.-The pregnancy toxemias or the Encymonic Atelosi_ tèses. N. Y. Paul B. Hocher, Inc., 1956.

Toxemias Gravídicas. Ponencia al II Congreso Nacional de Obstetricia y Ginecología de Cali. Delegación de Bogotá, I.C.S.S. 1955.

ZUSPAN, F. P.-The effect of maternal toxemia on fetal gonadal activity. Am. J. Obst. Gynec. 66: 46-53, 1955. 